\title{
Overexpression of SAPCD2 correlates with proliferation and invasion of colorectal carcinoma cells
}

\author{
Yage Luo ${ }^{1,2}$, Lili Wang ${ }^{1}$, Wenwen Ran' ${ }^{1}$ Guangqi Li ${ }^{1}$, Yujing Xiao ${ }^{1}$, Xiaonan Wang ${ }^{1}$, Han Zhao \\ and Xiaoming Xing ${ }^{1 *}$ (D)
}

\begin{abstract}
Background: Suppressor anaphase-promoting complex domain containing 2 (SAPCD2) is a novel gene playing important roles in the initiation, invasion, and metastasis of several malignancies. However, its role in colorectal carcinoma (CRC) still remains unclear.

Method: In this study, we investigated the expression and biological function of SAPCD2 in CRC. Immunohistochemistry (IHC) for SAPCD2 was performed in 410 pairs of CRC specimens and corresponding normal epithelial tissues, and in 50 adenoma tissues. Clinical pathological factors were analyzed in relation to the expression of SAPCD2. The biological functions of SAPCD2 in CRC cells and its effect on cell cycle were investigated in vitro and in vivo through gain/loss-of-function approaches.
\end{abstract}

Results: $I H C$ showed that SAPCD2 expression was significantly higher in CRC tissues compared to adenoma and normal epithelium tissues and was correlated with tumor location $(p=0.018)$. SAPCD2 significantly promoted cell proliferation, migration, and invasion both in vitro and in vivo $(p<0.05)$. In addition, SAPCD2 knockdown in CRC cells was associated with reduced $G_{1} / S$ transition, while overexpression caused $G_{2} / M$ phase arrest $(p<0.05)$.

Conclusions: In sum, SAPCD2 is overexpressed in CRC tissues and plays a critical role in CRC progression. Therefore, it might represent a promising therapeutic target for CRC treatment.

Keywords: Colorectal carcinoma, SAPCD2, Proliferation, Migration, Invasion, Cell cycle

\section{Background}

Colorectal cancer is one of the most common malignancies in the world, and its annual incidence in individuals younger than 55 years has continuously increased by almost $2 \%$ from the mid-1990s to 2014 [1]. However, the mechanisms regulating the development of colorectal cancer still remain elusive.

Suppressor anaphase-promoting complex domain containing 2 (SAPCD2), also known as p42.3 or C9orf140, is

\footnotetext{
*Correspondence: edithxing@126.com; Xingxm@qduhospital.cn

${ }^{1}$ Department of Pathology, The Affiliated Hospital of Qingdao University, 16 Jiangsu Road, Qingdao 266000, Shandong, People's Republic of China

Full list of author information is available at the end of the article
}

a cell cycle-dependent gene which was first identified in the gastric cancer (GC) cell line, BGC823 [2]. It is located in human chromosome 9q42.3 and encodes a 389-amino acid protein $(42.3 \mathrm{kDa})$ with functional $\mathrm{CC}$-domains at the $\mathrm{C}$-terminus and an $\mathrm{N}$-terminal EF-Hand domain [3-5].

Recently, several studies have reported that SAPCD2 is overexpressed in several kinds of solid tumors, including GC, hepatocellular carcinoma (HCC), melanoma, glioblastoma, and renal cell cancer (RCC) [2, 6-9], and might play important roles in cell proliferation, migration, and invasion by activating JAK/STAT, MAPK, and Wnt signaling pathways [3, 4, 7, 9]. Bioinformatics

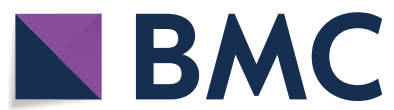

(c) The Author(s) 2020. This article is licensed under a Creative Commons Attribution 4.0 International License, which permits use, sharing, adaptation, distribution and reproduction in any medium or format, as long as you give appropriate credit to the original author(s) and the source, provide a link to the Creative Commons licence, and indicate if changes were made. The images or other third party material in this article are included in the article's Creative Commons licence, unless indicated otherwise in a credit line to the material. If material is not included in the article's Creative Commons licence and your intended use is not permitted by statutory regulation or exceeds the permitted use, you will need to obtain permission directly from the copyright holder. To view a copy of this licence, visit http://creativeco mmons.org/licenses/by/4.0/. The Creative Commons Public Domain Dedication waiver (http://creativecommons.org/publicdomain/ zero/1.0/) applies to the data made available in this article, unless otherwise stated in a credit line to the data. 
analysis in gastric cancer predicted a role of SAPCD2 in a signaling network also comprising S100A11, RAGE, P38, MAPK, microtubule-associated protein, spindle protein, and centromere protein, regulating cell proliferation, or in the Ras-Raf-1-MEK-MAPKK-MAPK pathway [3-5]. However, no functional experiments has confirmed this hypothesis. To date, little is known about the function of SAPCD2 in colorectal carcinoma (CRC).

In the present study, we conducted a retrospective research to investigate the relationship between the level of SAPCD2 expression and the clinical characteristics and overall survival (OS) of 410 Chinese Han CRC patients. In addition, we evaluated the biological role of SAPCD2 in cell proliferation, migration, invasion, and cell cycle in RKO and/or HCT116 cell lines. These findings provide new insights into the functions of SAPCD2 and its role in CRC.

\section{Materials and methods}

\section{Tissues and cell lines}

Four hundred and ten CRC specimens with matched adjacent normal epithelium tissues and 50 colorectal adenoma tissues were collected at the Affiliated Hospital of Qingdao University from 2014 to 2016. The tissues were obtained during colorectal surgery and were immediately fixed with $40 \mathrm{~g} / \mathrm{L}$ formaldehyde and embedded in paraffin wax. Tissue microarray was constructed by TMAjrTM according to the manufacturer's instructions (Pathology Devices, MD, USA). For quantitative real-time PCR (qRT-PCR) and western blot (WB) analysis, 20 sets of primary CRC tissues and distant normal epithelium tissues were obtained during colorectal cancer resection. Tissues were stored at $-80{ }^{\circ} \mathrm{C}$ for further use. None of the patients had received radiotherapy and chemotherapy before surgery. The protocol of this study and the informed consents were approved by the Ethics Committee of the Affiliated Hospital of Qingdao University.

Human CRC RKO and HCT116 cell lines (ATCC; Manassas, VA, USA) were cultured in Dulbecco's modified Eagles' medium (DMEM; Corning, 10-013-CVR, NY, USA) supplemented with $10 \%$ fetal bovine serum (FBS; Gibco, 16,000-044, NY, USA) and maintained at $37{ }^{\circ} \mathrm{C}$ in a humidified atmosphere with $5 \% \mathrm{CO}_{2}$.

\section{Immunohistochemistry}

Paraffin-embedded tissues were deparaffinized and rehydrated by xylene and a graded ethanol series. Sections were treated with $3 \%$ hydrogen peroxidase $(10 \mathrm{~min}$, room temperature), and antigen retrieval was performed with citrate buffer $(\mathrm{pH}=6.0)$ for $35 \mathrm{~min}$, followed by incubation with rabbit anti-SAPCD2 polyclonal antibody (1:1500; Abcam, ab126432, MA, USA) overnight at $4{ }^{\circ} \mathrm{C}$. Then, sections were incubated with polymer-HRP secondary antibody (ZSGB-Bio, MA2522, Beijing, China) for $20 \mathrm{~min}$ at room temperature and developed by a 3,3-diaminobenzidine (DAB) kit (ZSGB-Bio, ZL1-9017, Beijing, China), counterstained with hematoxylin.

All slides were examined and graded by two pathologists blinded to the clinical diagnosis. Cytoplasmic SAPCD2 was quantified based on the extent of positive tumor cells and the intensity of staining. The percentage of positive tumor cells was scored as 0 (negative), 1 (1-25\%), 2 (26-50\%), 3 (51-75\%), and 4 (>75\%). The staining intensity was scored as 0 (no staining), 1 (weak staining), 2 (moderate staining), and 3 (strong staining). The two scores were multiplied and the resulting immune-reactive score (IRS) (values from 0 to 12) was used to classify the samples into two categories: high level (4-12 scores) and low level (1-3 scores) [10].

\section{Quantitative real-time PCR analysis}

Total RNA was extracted from RKO and HCT116 cell lines by using Trizol (Pufei, 3101-100, Shanghai, China), the mRNA of SAPCD2 was examined by using SYBR Master Mixture (TAKARA, DRR041B, Dalian, China) and signals were measured by a LightCycler ${ }^{\circledR} 480$ System (Roche, Basel, Switzerland). Total RNA of 20 pairs of fresh tissues was extracted by using the RNAprep Pure Tissue Kit (TIANGEN Biotech, DP140916, Beijing, China), according to the manufacturer's instructions. Reverse transcription was performed using $1000 \mathrm{ng}$ of total RNA using the PrimeScriptTMRT reagent Kit (TAKARA, RR047A, Dalian, China), the mRNA expression of SAPCD2 was examined by using SYBR ${ }^{\circledR}$ Green PCR Master Mix (TAKARA, RP820A, Dalian, China) with gene-specific primers and real-time PCR Detection System (ABI, 7500, CA, USA).

For the analysis of SAPCD2 expression in RKO and HCT116 cell lines, the primer sequences were as follows: SAPCD2: 5'-GAGGTGACCGAGAAGAGTGAG$3^{\prime}(\mathrm{F})$ and 5'-GATGAAGGTGGAATCCAGAGG-3' (R); GAPDH: 5'-TGACTTCAACAGCGACACCCA-3' (F) and $5^{\prime}$-CACCCTGTTGCTGTAGCCAAA- $3^{\prime}$ (R). The thermal cycling conditions were as follows: pre-denaturation at $95{ }^{\circ} \mathrm{C}$ for $30 \mathrm{~s}, 40$ cycles of denaturation at $95{ }^{\circ} \mathrm{C}$ for $5 \mathrm{~s}$, annealing at $60{ }^{\circ} \mathrm{C}$ for $30 \mathrm{~s}$.

For the analysis of SAPCD2 expression in human tissues, the primer sequences were as follows: SAPCD2: 5'-GCTGAAGCAGATGAAGGAGCTGGAG-3' (F) and 5'-ACCGGGCCACCTCTTGTACCT-3' (R); GAPDH: $5^{\prime}$-CTGACTTCAACAGCGACACC-3' (F) and 5'-TGC TGTAGCCAAATTCGTTGT-3' (R). The thermal cycling conditions were as follows: pre-denaturation at $95{ }^{\circ} \mathrm{C}$ for $30 \mathrm{~s}, 40$ cycles of denaturation at $95^{\circ} \mathrm{C}$ for $10 \mathrm{~s}$, annealing at $60{ }^{\circ} \mathrm{C}$ for $30 \mathrm{~s}$, and extension at $72{ }^{\circ} \mathrm{C}$ for $1 \mathrm{~min}$. 
The SAPCD2 mRNA expression was measured by threshold cycle values $(\mathrm{Ct})$. The results were calculated using the $2^{-\Delta \Delta C t}$ method, and presented as fold changes.

\section{Western blot analysis}

Cells were lysed in RIPA buffer (CW2333S) supplemented with protease inhibitor cocktail (CW2200S) and phosphatase inhibitors (CW2383S). Total protein was extracted from 20 paired tissue samples by Tissue Protein Extraction Kit (CW0891M) (all from CWBIO, Beijing, China) and quantified with the Ultrospec ${ }^{\circledR} 3300$ Pro. Total proteins from cells $(30 \mu \mathrm{g})$ and tissues $(10 \mu \mathrm{g})$ were separated by $10 \%$ SDS PAGE and transferred to a polyvinylidene fluoride (PVDF) membrane (Millipore, IPVH00010, MA, USA) at $300 \mathrm{~mA}$ for $110 \mathrm{~min}$. After blocking with Tris-buffered saline containing Tween20 (TBST, 1000:1) and 5\% fat-free milk for $2 \mathrm{~h}$, the membranes were incubated at $4{ }^{\circ} \mathrm{C}$ overnight with antiSAPCD2 rabbit polyclonal antibody (1:1000; ab150707) and anti-GAPDH rabbit polyclonal antibody (1:4000; ab9485), and subsequently probed with secondary goat anti-rabbit antibodies (1:5000; ab6721) (all from Abcam, MA, USA) at room temperature for $1 \mathrm{~h}$. Signals were analyzed by a chemiluminescence system (Thermo Fisher Scientific, MA, USA).

\section{Plasmid construction and transfection, and lentivirus transduction}

The lentiviral vector containing the SAPCD2 sequence (GenBank accession number: NM_178448) was pLVshSAPCD2, the control vector was pLV-shControl, and the SAPCD2 overexpression plasmid was lenti-SAPCD2. All vectors were purchased from Shanghai Gene Chem Corporation (Shanghai, China). The transfection of pLVshSAPCD2 and pLV-shControl into RKO and HCT116 cells, and that of lenti-SAPCD2 overexpression and control plasmids into RKO cells were carried out according to the manufacturer's instructions. The transfection efficiency was monitored by fluorescence microscopy (OLYMPUS, IX71, Tokyo, Japan) and stably transfected cells were selected by G418 at a concentration of $1 \mathrm{mg} /$ $\mathrm{ml}$.

\section{MTT assay}

After transfection, RKO and HCT116 cells were seeded into 96-well plates at $1 \times 10^{3} /$ well and cultured for 1-5 days. MTT reagent (Genview, JT343, FL, USA) was added after $0,24,48,72,96$, and $120 \mathrm{~h}$ and removed after a $4 \mathrm{~h}$ incubation at $37^{\circ} \mathrm{C}$. The formazan crystals were dissolved with dimethylsulfoxide (DMSO) $(100 \mu \mathrm{l} /$ well). The absorbance at $490 \mathrm{~nm}$ was measured using a microplate reader (Tecan Infinite, Mannedorf, Switzerland).

\section{Colony formation assay}

For the colony formation assay, RKO and HCT 116 cells were seeded into 6 -well plates at $1 \times 10^{3}$ cells per well and cultured for 14 days. Colonies were fixed with ethanol and stained by GIEMSA for $20 \mathrm{~min}$ at room temperature.

\section{Celigo cell counting assay}

After transfection, RKO and HCT116 cells were plated into 96-well plates at $1 \times 10^{3} /$ well and cultured for 1-5 days. Cells were counted by the Celigo automated cell counter (Nexcelom Bioscience, MA, USA), and cell growth curves were delineated.

\section{Cell cycle analysis}

RKO and HCT116 cells were analyzed for DNA content by FACS Calibur flow cytometer (Millipore, MA, USA) according to previously described methods [11]. Briefly, cells were synchronized, harvested, and fixed with $70 \%$ ethanol at $4{ }^{\circ} \mathrm{C}$ overnight. After washing with ice-cold PBS, cells were stained with propidium iodide (PI, $50 \mu \mathrm{g} / \mathrm{ml}$ ), mixed with Triton X-100 and RNase A for $30 \mathrm{~min}$, and cell cycle was analyzed by a FACS Caliber flow cytometer (Beckman Coulter, CA, USA).

\section{Migration and invasion assays}

A total of $1 \times 10^{5}$ transfected cells were suspended in $200 \mu \mathrm{l}$ serum-free medium and placed in the upper compartment of a transwell chamber (24-well; Corning, NY, USA). The lower chamber was filled with culture medium containing $15 \%$ FBS as a chemoattractant and incubated for $72 \mathrm{~h}$. For the invasion assay, the inserts were pre-coated with extracellular matrix gel (BD Biosciences, MD, USA). After incubation, cells on the upper surface of the membrane were removed, and cells on the lower surface were fixed, stained with $0.1 \%$ crystal violet, and counted under a light microscope in five randomly picked fields.

\section{Animal experiments}

A murine xenograft model was developed to investigate the effects of SAPCD2 on tumor invasion in vivo. Fourweek old nude BALB/c-nu/nu mice were purchased from Shanghai Gene Chem Corporation. RKO cells were infected with pLV-shSAPCD2 or pLV-shControl, and $4 \times 10^{6}$ infected cells were injected into the right flank. Tumor growth was examined from the third week for 10 days. Tumor volume (V) was monitored by measuring the length $(\mathrm{L})$ and width $(\mathrm{W})$ of the tumor following the equation: $\mathrm{V}=\left(\mathrm{L} \times \mathrm{W}^{2}\right) \times 0.5$. Protocols of animal experiments were approved by the Affiliated Hospital of Qingdao University. 


\section{Statistical analysis}

All data were evaluated using SPSS 19.0.0 software (SPSS, Chicago, IL, USA) and expressed as mean \pm SD. All experiments were repeated at least 3 times. The relationship between the clinic pathological features and SAPCD2 expression, as well as the differences in SAPCD2 expression between normal epithelium, adenoma, and CRC tissues, were evaluated using a Chi square $\left(\chi^{2}\right)$ test. Survival analysis was performed by the Kaplan-Meier method. Statistical significance was calculated by a Student's two-sided $\mathrm{t}$ test and $\mathrm{p}$ values $<0.05$ were considered as significant.

\section{Results}

SAPCD2 expression is elevated in CRC tissues

IHC staining was performed to analyze the expression of SAPCD2 in CRC, adenoma, and normal epithelium tissues from $410 \mathrm{CRC}$ and 50 adenoma patients. As shown in Fig. 1a, the expression level of SAPCD2 was significantly elevated in CRC tissues compared to normal epithelial tissues, and the protein mainly localized in the cytoplasm of CRC cells.

SAPCD2 protein and mRNA levels were further examined by WB and quantitative real-time PCR in 20 pairs of fresh CRC specimens and associated normal epithelium tissues. As shown in Fig. 1b, c, SAPCD2

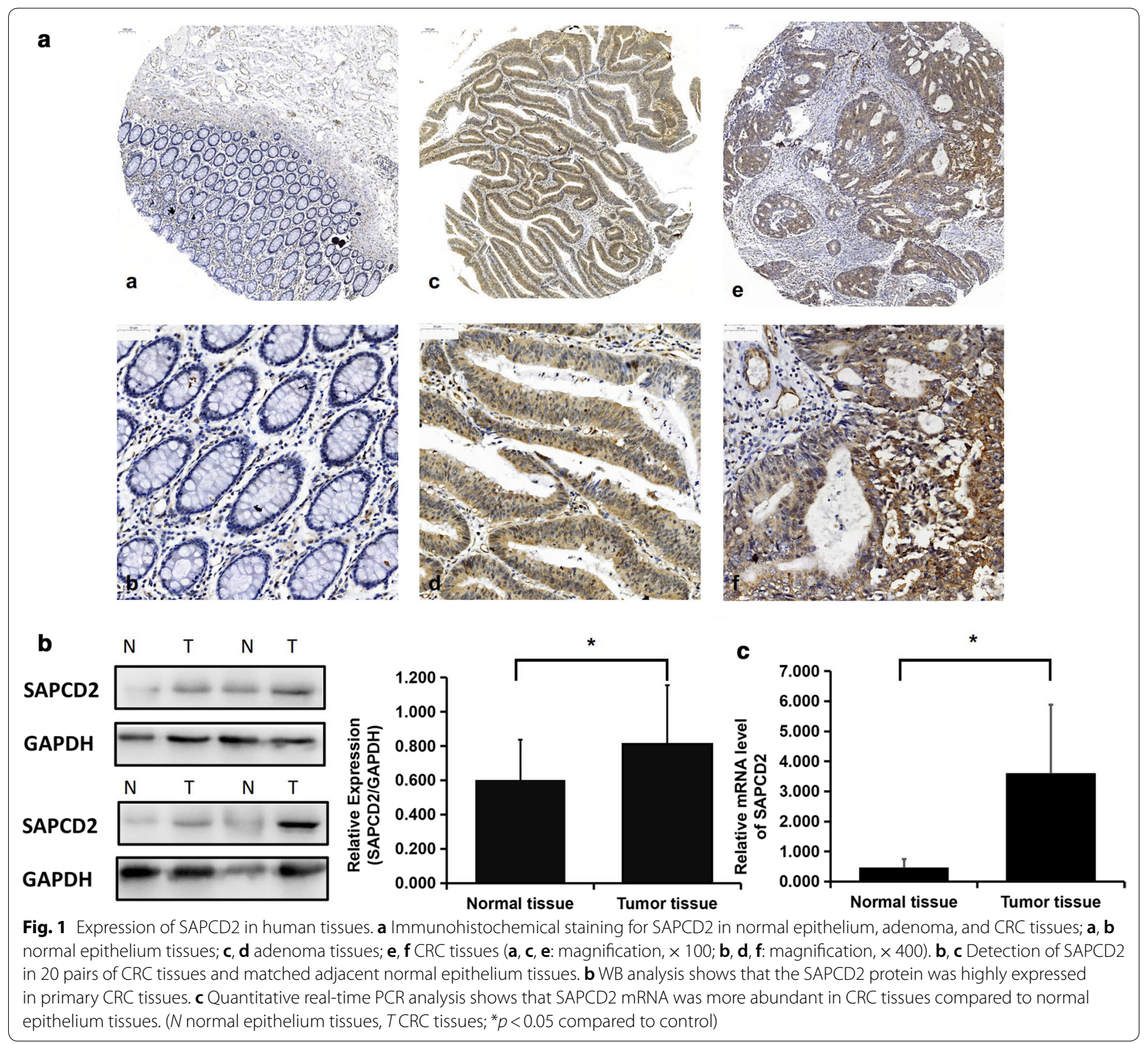


Table 1 SAPCD2 expression among the 50 adenoma tissues, 410 pair of CRC tissues and matched normal tissues

\begin{tabular}{lrcrr}
\hline Tissue groups & $\mathbf{n}$ & \multicolumn{2}{c}{ SAPCD2 expression } & p value \\
\cline { 3 - 4 } & & High (\%) & Low (\%) & \\
\hline Normal & 410 & $29(7.1)$ & $381(92.9)$ & \\
Adenoma & 50 & $9(18.0)$ & $41(82.0)$ & $<0.001$ \\
CRC & 410 & $228(55.4)$ & $182(44.6)$ & \\
\hline
\end{tabular}

Table 2 Correlations between the expression of SAPCD2 and clinic pathological characteristics $(n=410)$

\begin{tabular}{|c|c|c|c|c|}
\hline \multirow[t]{2}{*}{ Characteristics } & \multirow[t]{2}{*}{$\mathrm{n}$} & \multicolumn{2}{|c|}{ SAPCD2 expression } & \multirow[t]{2}{*}{$p$ value } \\
\hline & & High (\%) & Low (\%) & \\
\hline \multicolumn{5}{|l|}{ Gender } \\
\hline Male & 252 & $146(57.9)$ & $106(42.1)$ & \multirow[t]{2}{*}{0.231} \\
\hline Female & 158 & $82(51.9)$ & $76(48.1)$ & \\
\hline \multicolumn{5}{|l|}{ Age (years) } \\
\hline$\geq 50$ & 364 & $204(56.0)$ & $160(44.0)$ & \multirow[t]{2}{*}{0.619} \\
\hline$<50$ & 46 & $24(52.2)$ & $22(47.8)$ & \\
\hline \multicolumn{5}{|l|}{ Location } \\
\hline Right colon & 74 & $32(43.2)$ & $42(56.8)$ & \multirow[t]{2}{*}{0.018} \\
\hline Left colon & 336 & $196(58.3)$ & $140(41.7)$ & \\
\hline \multicolumn{5}{|l|}{ Tumor size (cm) } \\
\hline$\leq 6$ & 342 & $184(53.8)$ & $158(46.2)$ & \multirow[t]{2}{*}{0.098} \\
\hline$>6$ & 68 & $44(64.7)$ & $24(35.3)$ & \\
\hline \multicolumn{5}{|c|}{ Tumor differentiation } \\
\hline Well & 18 & $11(61.1)$ & $7(38.9)$ & \multirow[t]{3}{*}{0.070} \\
\hline Moderate & 301 & $176(58.5)$ & $125(41.5)$ & \\
\hline Poor & 91 & $41(45.1)$ & $50(54.9)$ & \\
\hline \multicolumn{5}{|l|}{ TNM stage } \\
\hline I & 55 & $28(50.9)$ & $27(49.1)$ & \multirow[t]{4}{*}{0.078} \\
\hline$\|$ & 138 & $77(55.8)$ & $61(44.2)$ & \\
\hline III & 127 & $63(49.6)$ & $64(50.4)$ & \\
\hline IV & 90 & $60(66.7)$ & $30(33.3)$ & \\
\hline \multicolumn{5}{|c|}{ Depth of invasion $(\mathrm{T})$} \\
\hline $\mathrm{T} 1$ & 12 & $8(66.7)$ & $4(33.3)$ & \multirow[t]{4}{*}{0.570} \\
\hline $\mathrm{T} 2$ & 67 & $36(53.7)$ & $31(46.3)$ & \\
\hline T3 & 149 & $88(59.1)$ & $61(40.9)$ & \\
\hline T4 & 182 & $96(52.7)$ & $86(47.3)$ & \\
\hline \multicolumn{5}{|c|}{ Lymph node metastasis (N) } \\
\hline NO & 229 & $127(55.5)$ & $102(44.5)$ & \multirow[t]{2}{*}{0.945} \\
\hline $\mathrm{N} 1+\mathrm{N} 2$ & 181 & $101(55.8)$ & $80(44.2)$ & \\
\hline
\end{tabular}

protein and mRNA were significantly more abundant in CRC than in normal tissues $(p=0.045, p<0.001$, respectively). Moreover, the expression of SAPCD2 among the normal epithelium tissues, adenoma tissues and CRC tissues was obviously different $(p<0.001)$ (Table 1).

The expression of SAPCD2 is related to clinico-pathological characteristics but not with overall survival

To analyze the association between SAPCD2 expression and clinico-pathological features, we used a Chi square $(x 2)$ test (Table 2). The expression level of SAPCD2 in the tumor samples of 410 patients was associated with left tumor location $(\mathrm{p}=0.018)$, but not with gender, age, TNM stage, or lymph node metastasis.

Of the 410 CRC patients, 13 were lost to follow-up. The survival curves indicated that the expression of SAPCD2 was not related to OS ( $p=0.746$; Fig. 2).

\section{SAPCD2 promotes proliferation, migration, and invasion of CRC cells}

Both the pLV-shSAPCD2 silencing vector and the lentiSAPCD2 overexpression vector were transfected into CRC cell lines. As shown by both quantitative real-time PCR and WB, SAPCD2 expression was significantly downregulated in pLV-shSAPCD2-transfected cells and upregulated in lenti-SAPCD2-transfected cells (all $p<0.05$ ) (Fig. 3 a, b).

MTT and Celigo cell counting assays demonstrated that SAPCD2 knockdown significantly inhibited RKO and HCT116 cell proliferation, whereas SAPCD2 overexpression promoted cell proliferation in RKO cells $(p<0.05$; Fig. $4 \mathrm{a}, \mathrm{c})$. The colony formation assay showed



Fig. 2 Overall survival (OS) curves of CRC patients. OS was correlated with the expression status of SAPCD2. No statistically significant difference was observed $(p>0.05)$ 


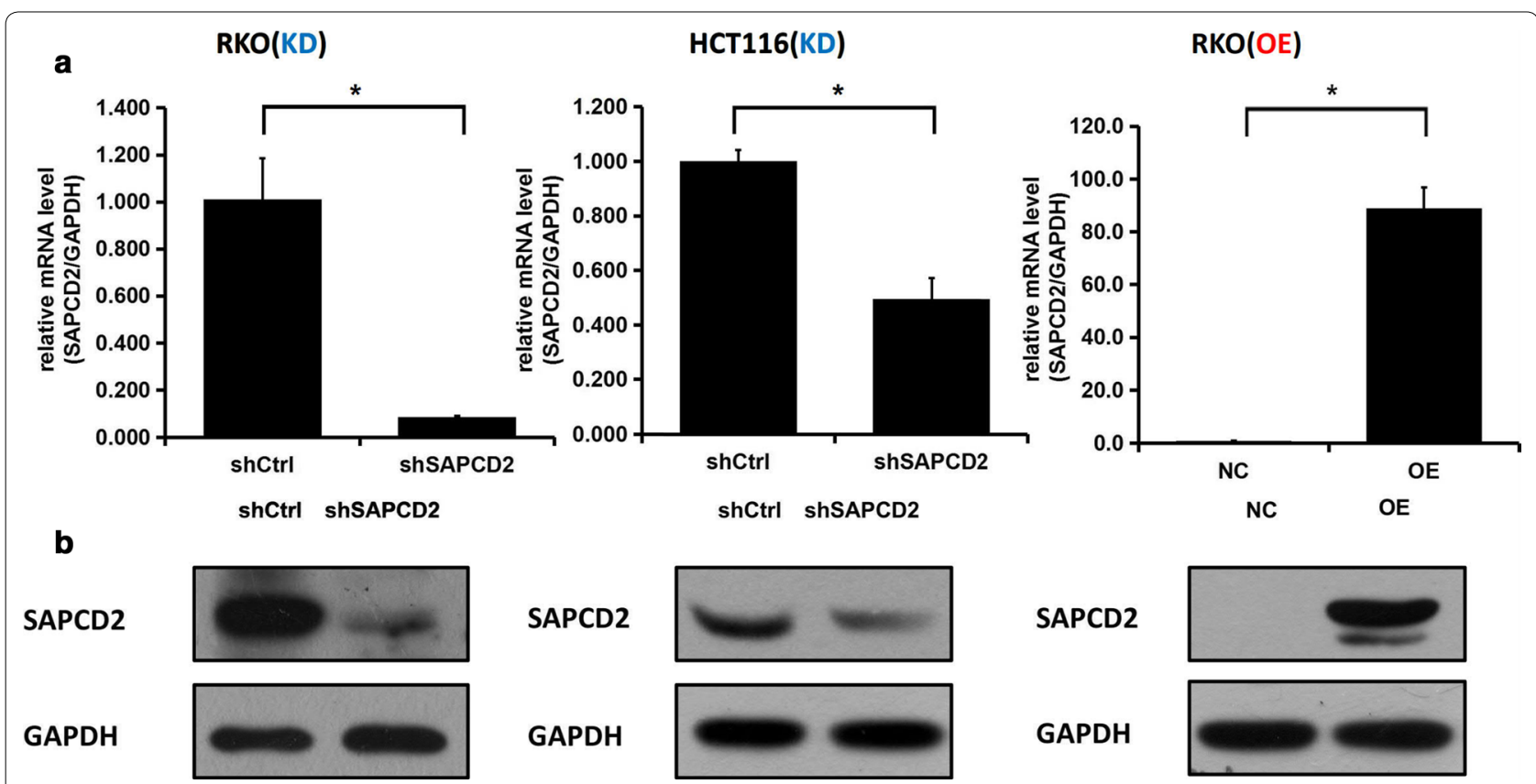

Fig. 3 Expression of SAPCD2 in CRC cells. a Quantitative real-time PCR and $\mathbf{b}$ WB were performed in RKO and HCT1 16 cells after transfection with pLV-shSAPCD2, pLV-shControl, lenti-SAPCD2 overexpression, or control plasmid. (KD knockdown, OE overexpression; ${ }^{*} p<0.05$ compared to control)

that SAPCD2 knockdown dramatically decreased the number of both RKO and HCT116 cell colonies, while its overexpression increased the colony number of RKO cells $(p<0.05$; Fig. 4b). The cell migration assay showed an obvious decrease in RKO and HCT116 cell migration upon SAPCD2 knockdown, while SAPCD2 overexpression promoted RKO cell migration ( $p<0.05$; Fig. $4 \mathrm{~d})$. Moreover, SAPCD2 knockdown significantly reduced the invasion capability of HCT116 cells $(p<0.05$; Fig. 4e). These results suggested that SAPCD2 was a crucial regulator of $\mathrm{CRC}$ cell proliferation, migration, and invasion.

\section{SAPCD2 induces the proliferation of CRC cells by affecting the cell cycle}

Flow cytometry was employed to investigate the effects of SAPCD2 on the cell cycle in RKO and HCT116 cells. We found that SAPCD2 knockdown lead to a significant peak of $G_{1}$ phase and an obvious decrease in $S$ phase in RKO cells, but a notably decrease in $G_{1}$ phase and an increase in S phase in HCT116 cells. However, SAPCD2 overexpression led to an obvious decrease in $\mathrm{S}$ phase and an increase in $\mathrm{G}_{2} / \mathrm{M}$ phase in RKO cells $(p<0.05$; Fig. 5$)$. These results indicated that SAPCD2 was implicated in the inhibition of $G_{1} / S$ transition and in the promotion of $\mathrm{G}_{2} / \mathrm{M}$ phase arrest.

\section{SAPCD2 knockdown suppresses tumor growth in vivo}

A murine xenograft model was developed by inoculating RKO cells, previously transfected with
pLV-shSAPCD2 or pLV-shControl, into BALB/c nude mice, and tumor size was measured every 2 days from the third week. We found that tumors deriving from pLV-shSAPCD2-transfected cells showed smaller size $(p<0.001)$ and lower weight $(p<0.001)$ than did tumors generated by pLV-shControl-transfected cells (Fig. 6b, c). These results indicated that SAPCD2 knockdown suppressed tumor growth in vivo.

\section{Discussion}

SAPCD2 has been reported to modulate malignant transformation and is considered as a potential biomarker of carcinogenesis [9, 10, 12, 13]. Consistently, it is upregulated in embryonic tissues, as well as in a number of human cancer cells, but not in normal tissues [14]. However, the biological functions of SAPCD2 in CRC are still unknown.

We found that SAPCD2 expression substantially differed in normal epithelium compared to adenoma and CRC tissues. Chen et al. reported that SAPCD2, besides being overexpressed in GC, was also associated with Helicobacter pylori inflammation and commonly expressed in chronic non-atrophic gastritis [15]. CRC usually develops from normal epithelium, which then transforms into adenoma and adenocarcinoma. Thus, adenoma is considered as a precancerous lesion $[16,17]$. Therefore, our results indicated that SAPCD2 could be an oncogene implicated in early stages of the transition from 

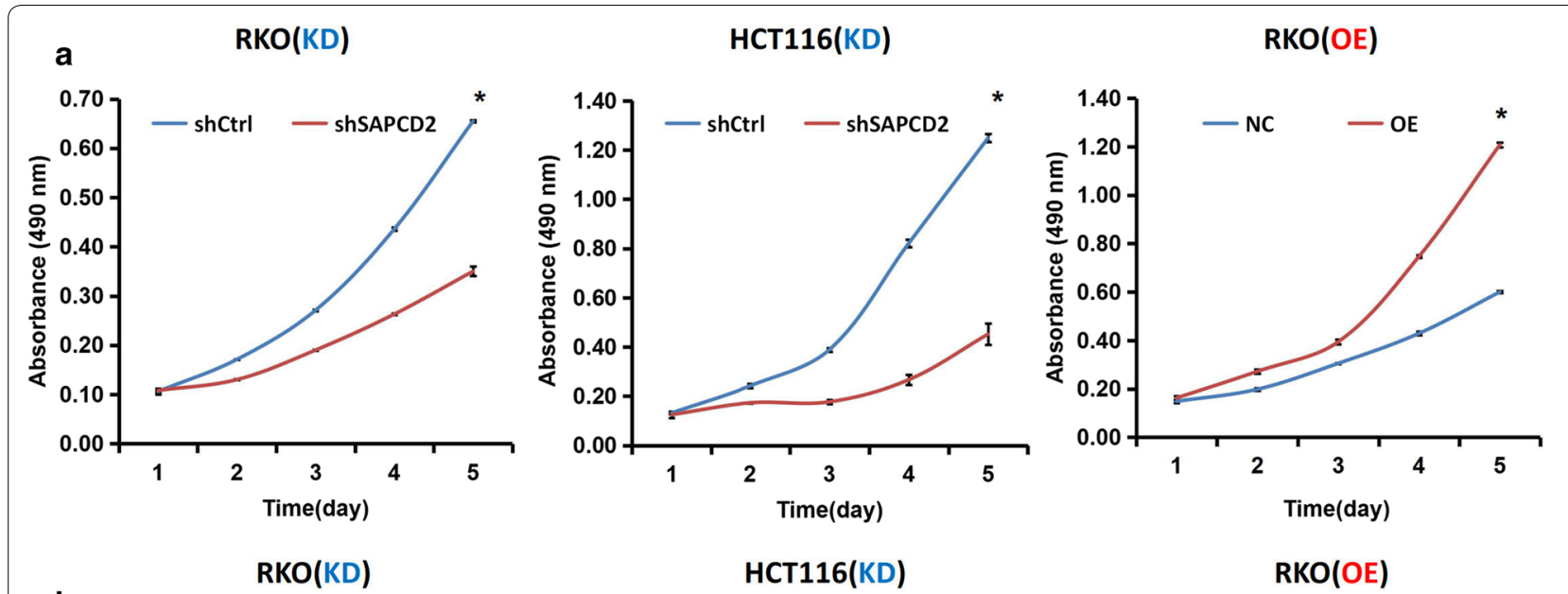

b
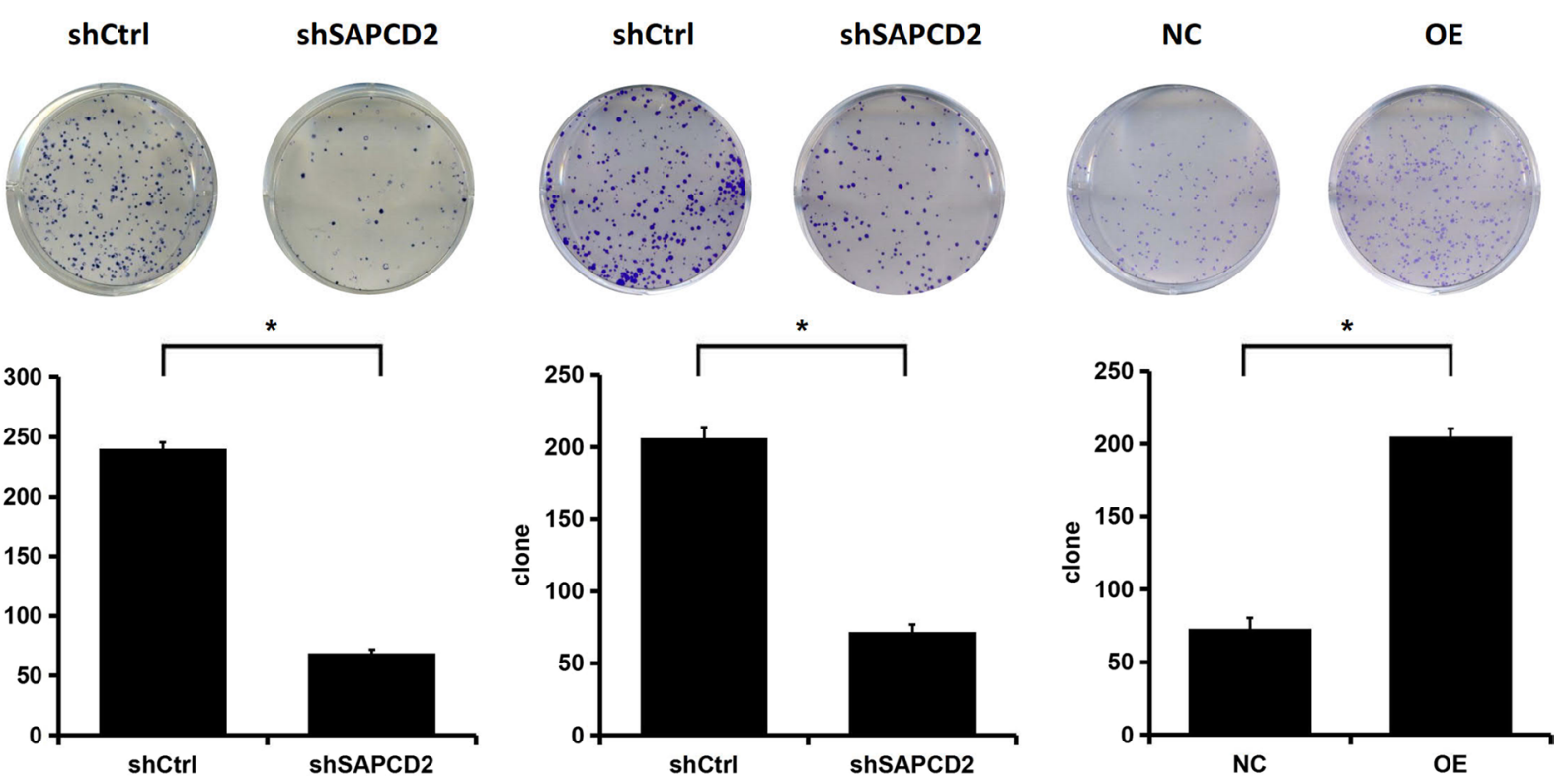

Fig. 4 Effects of SAPCD2 on proliferation, migration, and invasion of CRC cells in vitro. Transfection of RKO and HCT116 cells with pLV-shSAPCD2 or pLV-shControl and transfection of RKO cells with lenti-SAPCD2 overexpression or the corresponding control plasmid. a MTT assay was performed at 5 days post-transfection. $\mathbf{b}$ Colony formation assay was conducted after transfection and further incubation for 14 days. c Celigo Cell counting assay was performed at 5 days post-transfection. $\mathbf{d}$ Transwell migration and $\mathbf{e}$ invasion were analyzed at $72 \mathrm{~h}$ post-transfection. All data are from three independent experiments and expressed as mean \pm SD. (KD knockdown, OE overexpression; ${ }^{*} p<0.05$ compared to control)

normal epithelium to CRC. However, the exact function of SAPCD2 in this transition is unclear.

The expression of SAPCD2 has been reported to be related to gender, age, location, pathological classification, degree of infiltration, and the presence of lymphatic metastasis $[10,14]$. Our study also showed that enhanced expression of SAPCD2 was significantly associated with left tumor location, as well as increased cell migration, invasion, and proliferation. A recent research reported that SAPCD2-negative CRC patients showed better survival [14]. However, in our study, no significant association between SAPCD2 expression and OS was observed.
Further investigations, based on extended follow-up periods, need to be conducted to clarify this issue.

We found that SAPCD2 knockdown in RKO cells strongly inhibited cell proliferation and migration, SAPCD2 knockdown in HCT116 cells obviously inhibited cell proliferation, migration and invasion in vitro. Consistently, SAPCD2 silencing in RKO cells significantly reduced their in vivo tumorigenicity in nude mice. Conversely, SAPCD2 overexpression in RKO cells stimulated cell proliferation and migration. These results indicate a role of SAPCD2 in CRC progression. 


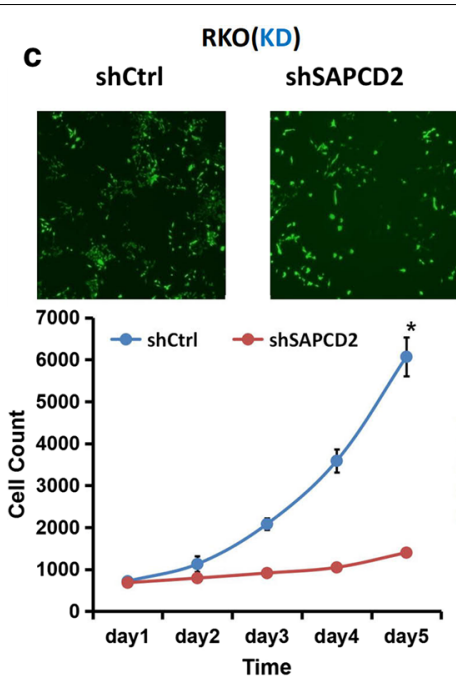

d

RKO(KD)
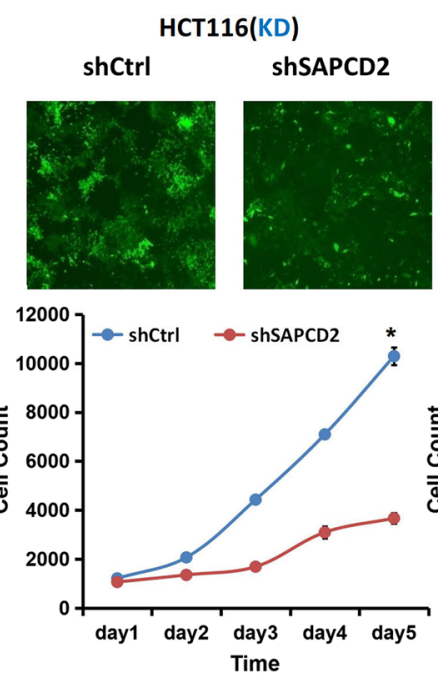

HCT116(KD)

ShSAPCD2

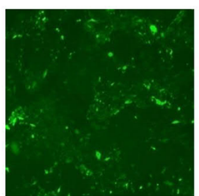

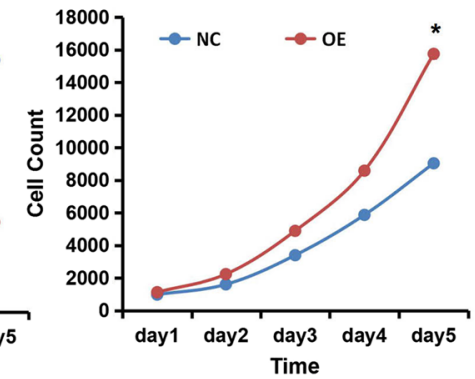

RKO(OE)

shCtrl shSAPCD2

shCtrl

ShSAPCD2

NC

$\mathrm{OE}$
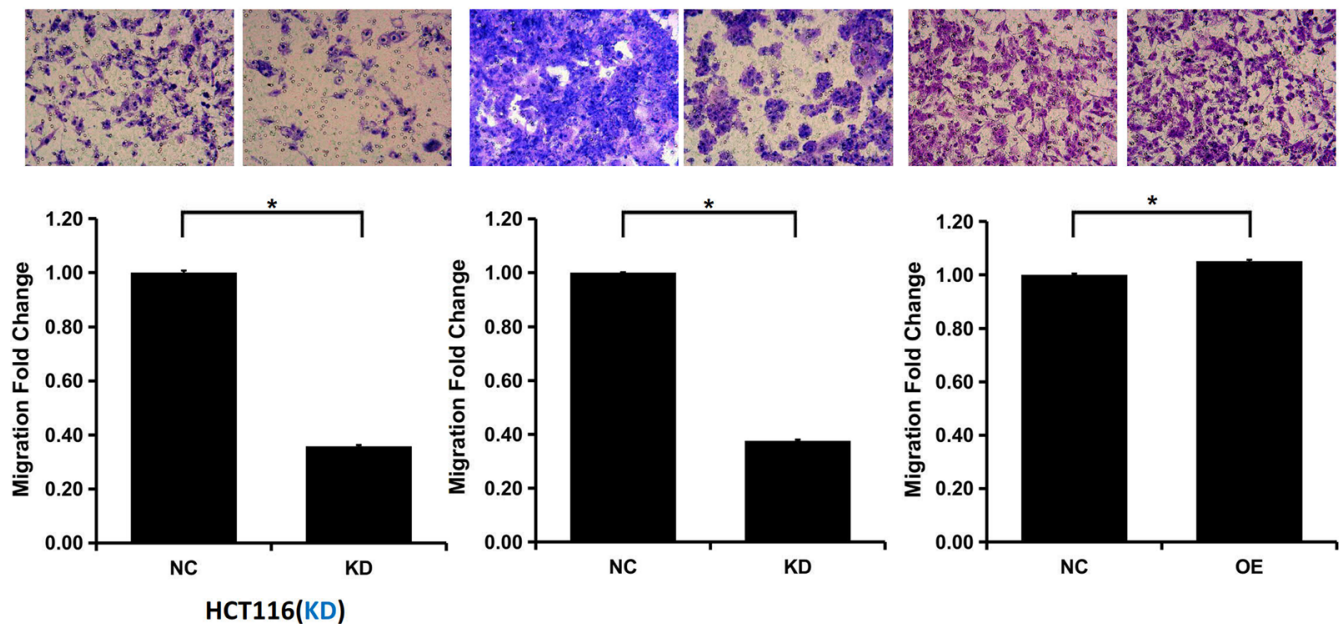

e shCtrl shSAPCD2


Fig. 4 (continued) 


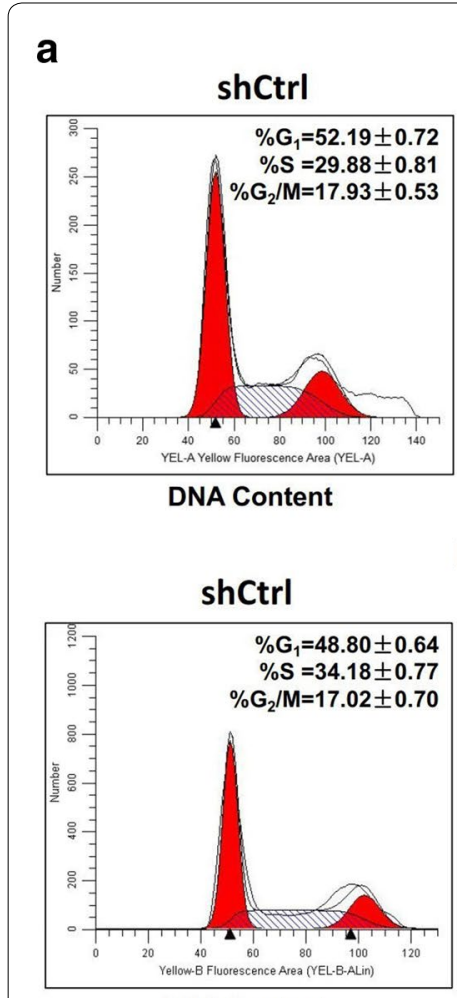

DNA Content
RKO(KD)



DNA Content

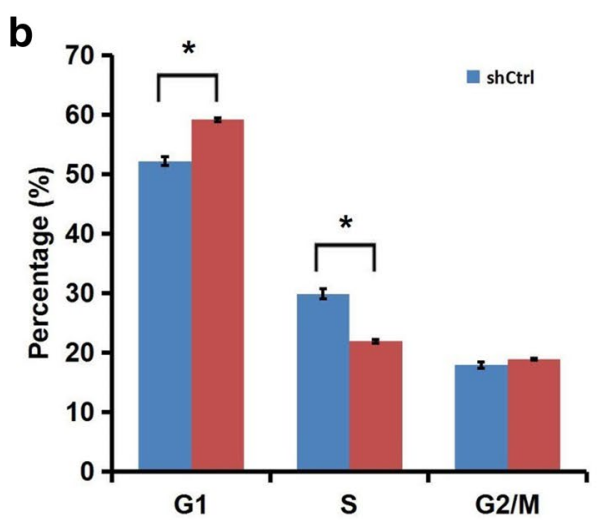

HCT116(KD)



DNA Content

RKO(OE)

NC

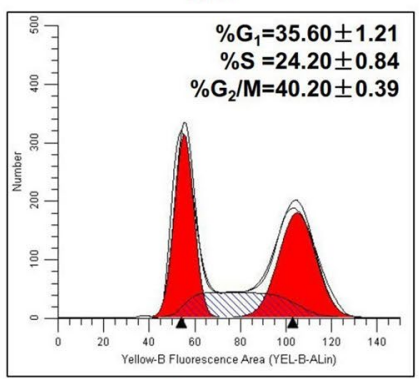

DNA Content

OE

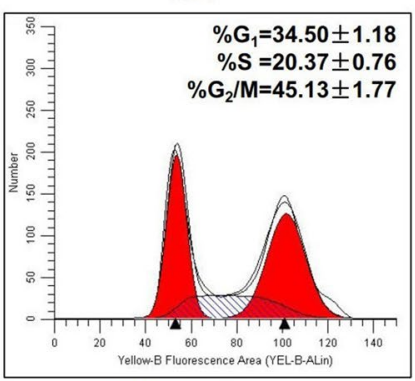

DNA Content
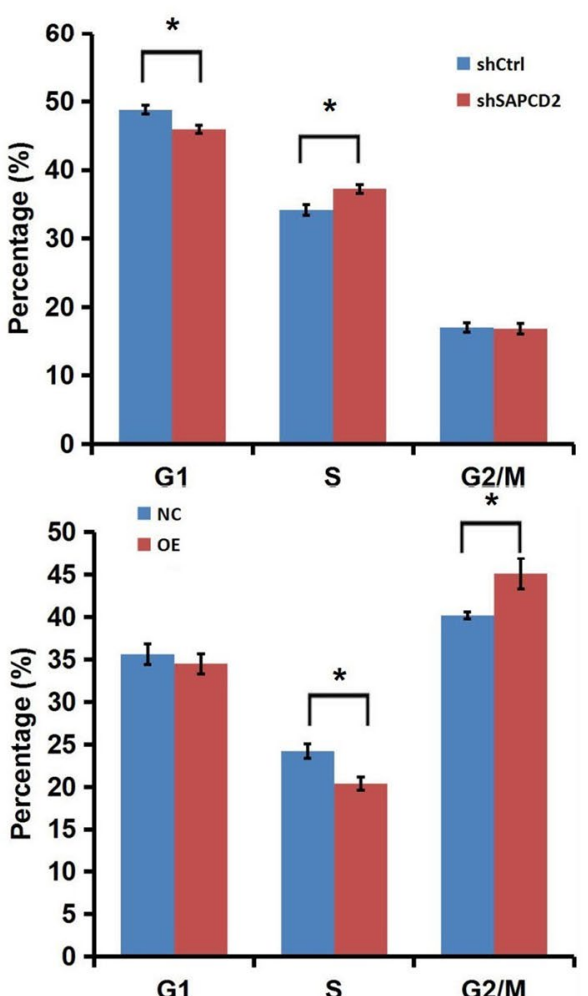

Fig. 5 Impact of SAPCD2 on cell cycle. a, b Cell cycle profiles were analyzed after the transfection of RKO and HCT116 cells with pLV-shSAPCD2 or pLV-shControl, and transfection of RKO cells with lenti-SAPCD2 overexpression or control plasmid. All data are from three independent experiments and expressed as mean $\pm S D$. (KD knockdown, OE overexpression; ${ }^{*} p<0.05$ compared to control)

Our findings support the hypothesis that SAPCD2 is involved in cell cycle regulation. SAPCD2 was initially identified by mRNA differential display (mRNADD) combined with cell cycle synchronization $[2,18]$. Several studies have shown that the expression of SAPCD2 in $G_{1}$ and $M$ phases is higher than that during $S$ and $G_{2}$ phases [2, 3, 19], and cell cycle dysregulation is known to be associated with cancer progression [20, 21]. Previous studies have shown that SAPCD2 expression is closely associated with Cyclin B1 and Chk2, as SAPCD2 knockdown promotes the down-regulation of Cyclin B1 and up-regulation of Chk2, while SAPCD2 overexpression promotes the up-regulation of Cyclin B1 $[6,18]$. As key cell cycle-dependent genes, Cyclin B1 and Cdc2 are involved in the $G_{2}-M$ phase transition, controlling the entry in $M$ phase, exit, and promoting uncontrolled cell proliferation [22]. Chk2 is another key gene involved in $\mathrm{M}$ phase regulation, which phosphorylates and sequesters Cdc25 in the cytoplasm, thereby suppressing the dephosphorylation of CycliB1/Cdc2 and inhibiting 



Fig. 6 In vivo effects of SAPCD2 knockdown in a murine xenograft model. a Tumor formation in nude mice 24 days after injection with RKO cells transfected with pLV-ShSAPCD2 or pLV-shControl virus. b Volumes of the tumor generated in nude mice were measured every 2 days after the injection with RKO cells, starting from the third week. c Weight of tumors generated by transfected RKO cells 24 days after the initial injection. All data are from three independent experiments and expressed as mean $\pm S D$. (KD knockdown, OE overexpression; $n=20 ;{ }^{*} p<0.05$ compared to control)

mitosis [23, 24]. However, there were no changes in the expression of Cdc25 and Cdc2 [6, 19]. In this study, we observed that SAPCD2 knockdown was associated with the inhibition of the $G_{1} / S$ transition, while SAPCD2 overexpression led to arrest in $G_{2} / M$ phase. Does SAPCD2 overexpression cause $\mathrm{G}_{2} / \mathrm{M}$ phase arrest by upregulating Cyclin B1 and downregulating Chk2, which further result in the wrong chromosome segregation and mitotic progression? However, further investigation still need to ascertain the molecular mechanisms involved in the control of cell proliferation in $G_{1}$ and $G_{2} / M$ phase.

The signaling pathways involved in SAPCD2-mediated regulation of solid tumor progression are still unknown. Epithelial-mesenchymal transition (EMT) is critical for tumorigenesis and is required for invasion and metastasis of various types of tumors [25-27]. Several studies have reported that SAPCD2 suppresses E-cadherin expression $[9,10,12]$, and a reduced E-cadherin level is closely correlated with cancer progression and invasion. Previous bioinformatics analysis indicated that the expression of SAPCD2 in GC might be regulated by the MAPK pathway via the APC and members of the S100 family, which are highly homologous to the $\mathrm{CC}$ and EF-hand structural domain of SAPCD2 [3-5]. Notably, both S100 and APC are implicated in tumor progression [28-31]. A role of SAPCD2 in the promotion of tumor metastasis and EMT progression through Wnt, MAPK, and PI3K/AKT has been proposed in melanoma and renal cell cancer [7, 9]. Weng et al. have found that the inhibition of the JAK/ STAT, MAPK, and Wnt signaling pathways downregulates the expression of SAPCD2, which was also found to be controlled by STAT5, EZH2, and $\beta$-catenin. Moreover, STAT5 enhanced the expression of SAPCD2 by recruiting $\mathrm{EZH} 2$ and $\beta$-catenin [10].

\section{Conclusion}

In sum, our findings demonstrated that the expression of SAPCD2 is higher in CRC tissues than in normal epithelium and is involved in the "normal epitheliumadenoma-CRC" transition. SAPCD2 strongly affected cell proliferation, migration, and invasion. The effects of SAPCD2 on cell proliferation were correlated with $G_{1} / S$ inhibition and cell arrest in $G_{2} / M$. Our study provides 
new evidence for the role of SAPCD2 in CRC. The elucidation of the precise molecular events responsible for the SAPCD2-mediated effects is imperative for the development of new therapies in CRC. Further studies should be conducted on the related signaling pathway with SAPCD2 in the progression of colorectal cancer.

\begin{abstract}
Abbreviations
SAPCD2: Suppressor anaphase-promoting complex domain containing 2; CRC: Colorectal carcinoma; GC: Gastric cancer; RCC: Renal cell cancer; HCC: Hepatocellular carcinoma; OS: Overall survival; IHC: Immunohistochemistry; GRT-PCR: Quantitative real-time PCR; WB: Western blot; PVDF: Polyvinylidene fluoride; SDS-PAGE: Sodium dodecyl sulfatepolyacrylamide gel electrophoresis; TBST: Tris-buffered saline tween-20; GAPDH: Glyceraldehyde-3-phosphate dehydrogenase; EZH2: Enhancer of zeste homolog 2; STAT5: Signal transducer and activator of transcription 5; EMT: Epithelial-mesenchymal transition; mRNADD: mRNA differential display.
\end{abstract}

\section{Acknowledgements}

Not applicable.

\section{Authors' contributions}

YL conceived and designed the experiments, performed the experiments, wrote the paper. LW conceived and designed the experiments, reviewed drafts of the paper. WR performed the experiments, contributed reagents/ materials/analysis tools. GL performed the experiments, contributed analysis tool. YX prepared figures and/or tables. XW prepared figures and/or tables. $\mathrm{HZ}$ analyzed the data. XX conceived and designed the experiments, contributed reagents/materials/analysis tools, wrote the paper, reviewed drafts of the paper. All authors read and approved the final manuscript.

\section{Funding}

This work was supported by following funds: National Natural Science Foundation of China (Grant No. 81201947, 81972329)/Natural Science Foundation of Shandong (Grant No. ZR2009CM014)/Excellent Young Scientist Foundation of Shandong Province (Grant No. 2006BSB14001)/Qingdao Minsheng Science and Technology Project (Grant No. 17-3-3-38-nsh).

\section{Availability of data and materials}

The datasets used and/or analyzed during the current study are available from the corresponding author on reasonable request.

\section{Ethics approval and consent to participate}

The study protocol and informed consent had been examined and certified by the Ethics Committee of the Affiliated Hospital of Qingdao University. Animal care was according to the animal feeding guidelines of the Affiliated Hospital of Qingdao University. License to conduct live animal experiments was approved by Ethics Committee of the Affiliated Hospital of Qingdao University.

\section{Competing interests}

The authors declare that they have no competing interests.

\section{Consent for publication}

Not applicable.

\author{
Author details \\ ${ }^{1}$ Department of Pathology, The Affiliated Hospital of Qingdao University, \\ 16 Jiangsu Road, Qingdao 266000, Shandong, People's Republic of China \\ 2 Department of Pathology, Qingdao University Basic Medicine College, Qing-
} dao 266000, Shandong, People's Republic of China.

Received: 29 August 2019 Accepted: 22 January 2020

Published online: 06 February 2020

\section{References}

1. Siegel RL, Miller KD, Jemal A. Cancer statistics, 2018. CA Cancer J Clin. 2018;68(1):7-30.

2. Xu X, Li W, Fan X, Liang Y, Zhao M, Zhang J, et al. Identification and characterization of a novel p42.3 gene as tumor-specific and mitosis phasedependent expression in gastric cancer. Oncogene. 2007;26(52):7371-9.

3. Zhang JL, Lu CL, Shang ZG, Xing R, Shi L, Lv YY. p42.3 gene expression in gastric cancer cell and its protein regulatory network analysis. Theor Biol Med Model. 2012:9(1):53-62.

4. Hao Y, Fan T, Nan K. Optimization and corroboration of the regulatory pathway of p42.3 protein in the pathogenesis of gastric carcinoma. Comput Math Method Med. 2015;2015: 683617-79.

5. Liu X, Hao Y, Fan T, Nan K. Application of intelligent algorithm in the optimization of novel protein regulatory pathway: mechanism of action of gastric carcinoma protein p42.3. J Cancer Res Ther. 2016;12(2):650-6.

6. Sun W, Dong WW, Mao LL, Li WM, Cui JT, Xing R, et al. Overexpression of p42.3 promotes cell growth and tumorigenicity in hepatocellular carcinoma. World J Gastroenterol. 2013;19(19):2913-20.

7. Liu H, Zhu M, Li Z, Wang Y, Xing R, Lu Y, et al. Depletion of p42.3 gene inhibits proliferation and invasion in melanoma cells. J Cancer Res Clin Oncol. 2017;143(4):639-48.

8. Wan W, Xu X, Jia G, Li W, Wang J, Ren T, et al. Differential expression of p42.3 in low- and high-grade gliomas. World J Surg Oncol. 2014;12(1):185-92.

9. Li P, Cao WJ, Mao LL, Huang H, Zheng JN, Pei DS. p42.3 promotes cell proliferation and invasion in human renal-cell carcinoma. Int J Clin Exp Med. 2014;7(12):4959-66.

10. Weng YR, Yu YN, Ren LL, Cui Y, Lu YY, Chen HY, et al. Role of C9orf140 in the promotion of colorectal cancer progression and mechanisms of its upregulation via activation of STAT5, beta-catenin and EZH2. Carcinogenesis. 2014;35(6):1389-98.

11. Zhou X, Xing X, Zhang S, Liu L, Wang C, Li L, et al. Glucose-regulated protein 78 contributes to the proliferation and tumorigenesis of human colorectal carcinoma via AKT and ERK pathways. Oncol Rep. 2016;36(5):2723-30

12. Cao WJ, Du WQ, Mao LL, Zheng JN, Pei DS. Overexpression of p42.3 promotes cell proliferation, migration, and invasion in human gastric cancer cells. Tumor Biol. 2016;37(9):12805-12.

13. Cao WJ, Mao LL, Zheng JN, Pei DS. p42.3:an abductor of cell cycle. AntiCancer Agent Med Chem. 2015;15(2):157-62.

14. Yuan XS, Zhang Y, Guan XY, Dong B, Zhao M, Mao LL, et al. p42.3: a promising biomarker for the progression and prognosis of human colorectal cancer. J Cancer Res Clin Oncol. 2013;139(7):1211-20.

15. Chen P, Cui Y, Fu QY, Lu YY, Fang JY, Chen XY. Positive relationship between p42.3 gene and inflammation in chronic non-atrophic gastritis. J Dig Dis. 2015;16(10):568-74.

16. Hill MJ, Morson BC, Bussey HJ. Aetiology of adenoma-carcinoma sequence in large bowel. Lancet. 1978;8(58):245-7.

17. Risio M. The natural history of colorectal adenomas and early cancer. Pathologe. 2012;33(S2):206-10.

18. Cui Y, Su WY, Xing J, Wang YC, Wang P, Chen XY, et al. MiR-29a inhibits cell proliferation and induces cell cycle arrest through the downregulation of p42.3 in human gastric cancer. PloS One. 2011;6(10):e25872-9.

19. Mao L, Sun W, Li W, Cui J, Zhang J, Xing R, et al. Cell cycle-dependent expression of $\mathrm{p} 42.3$ promotes mitotic progression in malignant transformed cells. Mol Carcinog. 2014;53(5):337-48.

20. Schwartz G, Shah MA. Targeting the cell cycle: a new approach to cancer therapy. J Clin Oncol. 2005;23(36):9408-21.

21. Williams GH, Stoeber K. The cell cycle and cancer. J Pathol. 2012;226(2):352-64

22. Gavet $\mathrm{O}$, Pines J. Progressive activation of CyclinB1-Cdk1 coordinates entry to mitosis. Dev Cell. 2010;18(4):533-43.

23. Golan A, Pick E, Tsvetkov L, Nadler Y, Kluger H, Stern DF. Centrosomal Chk2 in DNA damage responses and cell cycle progression. Cell Cycle. 2010;9(13):2647-56.

24. Malumbres M, Barbacid M. Cell cycle, CDKs and cancer: a changing paradigm. Nat Rev Cancer. 2009;9(3):153-66.

25. Lamouille S, Xu J, Derynck R. Molecular mechanisms of epithelial-mesenchymal transition. Nat Rev Mol Cell Biol. 2014;15(3):178-96.

26. De CB, Berx G. Regulatory networks defining EMT during cancer initiation and progression. Nat Rev Cancer. 2013;13(2):97-110. 
27. Thiery JP, Acloque H, Huang RY, Nieto MA. Epithelial-mesenchymal transitions in development and disease. Cell. 2009;139(5):871-90.

28. Santamaria-Kisiel L, Rintala-Dempsey AC, Shaw GS. Calcium-dependent and -independent interactions of the $\mathrm{S} 100$ protein family. Biochem J. 2006;396(2):201-14.

29. Grace A, Butler D, Gallagher M, Al-Agha R, Xin Y, Leader M, et al. APC gene expression in gastric carcinoma: an immunohistochemical study. Appl Immunohistochem Mol Morphol. 2002;10(3):221-4.

30. He TC, Sparks AB, Rago C, Kinzler KW. Identification of c-MYC as a target of the APC pathway. Science. 1998;281(5382):1509-12.
31. Hutchins JR, Toyoda Y, Hegemann B, Peters JM. Systematic analysis of human protein complexes identifies chromosome segregation proteins. Science. 2010:328(5978):593-9.

\section{Publisher's Note}

Springer Nature remains neutral with regard to jurisdictional claims in published maps and institutional affiliations.
Ready to submit your research? Choose BMC and benefit from:

- fast, convenient online submission

- thorough peer review by experienced researchers in your field

- rapid publication on acceptance

- support for research data, including large and complex data types

- gold Open Access which fosters wider collaboration and increased citations

- maximum visibility for your research: over $100 \mathrm{M}$ website views per year

At BMC, research is always in progress.

Learn more biomedcentral.com/submissions 